\title{
Wash and Wear Finishing of Cotton Fabrics by Loop Transfer Applicator
}

\author{
Shizuo Kubota ${ }^{* 1}$ and Robert J. Harper, Jr. ${ }^{* 2}$ \\ *1 Industrial Technology Center of Wakayama Prefecture, 60, Ogura, Wakayama-city, 649-62 Japan \\ ${ }^{* 2}$ Southern Regional Research Center, 1100, Robert E. Lee Blvd., P.O. Box 19687, New Orleans, \\ 70179 U. S. A.
}

\begin{abstract}
Cotton fabrics were wash and wear finished with a loop transfer applicator, one of low wet pickup finishing apparatus. A resin solution was applied evenly to the fabrics at a low pick-up, where no resin migration occurred on drying, so that the reduction of strength might be lessened and the durable press properties and the wrinkle recovery might be enhanced. As a crosslinking agent, dimethyloldihydroxy. ethyleneurea, and as acidic catalyst, $\mathrm{MgCl}_{2} \cdot 6 \mathrm{H}_{2} \mathrm{O}$ and glycolic acid were used and the add-on (pick-up) of the resin solution was adjusted to about $30 \%$. In comparison to the ordinary finishing, the reduction of the strength in tensile and tearing in the low wet pick-up finishing was lower for any of the finished fabrics, at the same level of the durable press properties. The pretreatment with thermoplastic resins prevented the reduction of the tensile strength.
\end{abstract}

\section{Introduction}

The easy-care finishing of cotton fabrics always re duces their strengths. Various finishing methods for pre. venting the reduction of the strengths have been investigated [ 1 ]. It is supposed that the causes of the strength reduction lie in the distortion of cotton fibers by crosslinking [ 2$]$, the formation of a surface-resin due to migration on drying, the degradation of cellulose with acid catalysts, and so forth.

In this study, a resin solution was applied evenly to fabrics at a wet pick-up of $40 \%$ and lower, where no migration of the resin occurs on drying [ 3 ], so that the reduction of strength might be depressed and the durable press properties (the smoothness of a fabric at the surface after washing, hereinafter abbreviated as DP) might be enhanced. The low wet pick-up finishing contributes to the saving of chemicals and energy.

As apparatus for the low wet pick-up finishing, lick rollers, spray applicators, liquor metering by engraved or spiraled rollers, foam applicators, loop transfer appli. cators, vacuum slot extractors, curved blade applicators, and so forth are useful $[3,4]$. In the investigation by Harper, a sheeting was finished with a loop transfer applicator in order to depress the reduction of abrasion re- sistance [5].

In this study, cotton fibers were wash and wear finished with a loop transfer applicator. The finished fabrics exhibited less reductions in tensile and tearing strengths and good hand.

\section{Experimental}

\subsection{Materials}

Fabrics finished : For thin cotton fabrics, were used ammonia - mercerized sheetings $\left(137.52 \mathrm{~g} / \mathrm{m}^{2}\right)$, scoured, bleached print cloths $\left(114.11 \mathrm{~g} / \mathrm{m}^{2}\right)$ and scoured. bleached, sodium hydroxide - mercerized print cloths $\left(121.76 \mathrm{~g} / \mathrm{m}^{2}\right)$, and for thick ones, scoured, bleached twill $\left(219.92 \mathrm{~g} / \mathrm{m}^{2}\right)$ and scoured, bleached, sodium hy droxide - mercerized twill $\left(232.39 \mathrm{~g} / \mathrm{m}^{2}\right)$.

The following agents were used : Dimethyloldihy. droxyethyleneurea (DMDHEU) (National Starch \& Chem ical Corp., Hylite LF, $40 \%$ ), $\mathrm{MgCl}_{2} \cdot 6 \mathrm{H}_{2} \mathrm{O}$ crystal (J. T. Barker Inc.), glycolic acid (Eastman, 70\%), a polyethylene softener (Alkalil Chem. Inc., Velvetol 17\%), a silicone softener (Sandoz Chemicals Corp., Sandopern FE Liquid 50\% ; Dow Corp., Dow Corning 1111 emulsion $38 \%$ used with $T L-41)$, and a nonionic wetting agent (Conoco Petrochemicals, Continental Oil Co., Aifonic 1012-60). As a thermoplastic resin, Hystretch V.29 
(BF Goodrich Co., poly (acrylonitrile-butadiene) elastomer emulsion. 44.5\%), and Airfiex Copolymer Emulsion TL-41 (Air Products \& Chemicals, Inc., polyacrylic ester, $\left.\mathrm{Tg}=-15^{\circ} \mathrm{C}, 50 \%\right)$ were used.

The concentrations of the finishing agents listed in the tables are expressed in $\mathrm{W} / \mathrm{W} \%$.

\subsection{Finishing}

The loop transfer applicator is shown in Fig. 1. The loop was made of cotton knitting. The amount of pick-up was controlled by changing the pressure between rolls 2 and 3. at constant pressure of $4.2 \mathrm{~kg} / \mathrm{cm}^{2}$ between 1 and 2. Moreover, for finishing, the time by which the fabric was passed through between the rolls was changed to adjust the pick-up to ca. $30 \%$. Thereafter, the fabric was preliminarily dried at $60{ }^{\circ} \mathrm{C}$ for $7 \mathrm{~min}$, steam pressed,

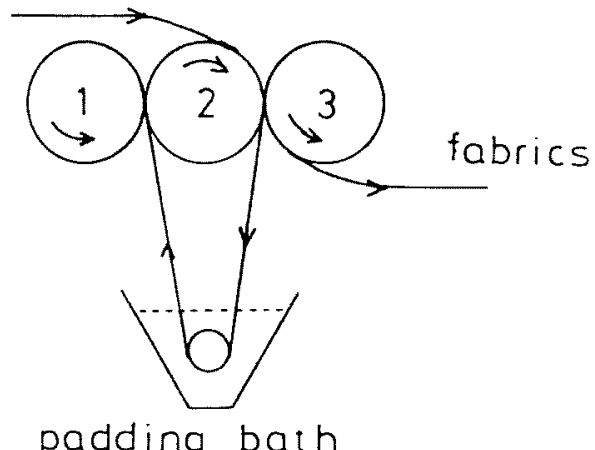

Fig. 1 Loop transfer applicator. cured at $160{ }^{\circ} \mathrm{C}$, washed one time with a Kenmore washing machine, tumble dried for $30 \mathrm{~min}$, and let to stand for $12 \mathrm{~h}$. Then, the add-on, the DP properties and so forth of the fabric were determined. For comparison. the ordinary finishing [ 6 ] was carried out ; the resin solution was applied by two dips-two nips method (squeezing at $3.5 \mathrm{~kg} / \mathrm{cm}^{2}$ ), preliminarily dried and cured under the same conditions as described above.

\subsection{Physical Properties}

The tensile strength was determined by the grab method with a Scott tester, the tearing strength by the Elmendorf method, and the wrinkle recovery by the Monsanto method. The DP degree was evaluated by using AATCC TM 124 replicas.

\section{Results and Discussion}

As thin cotton fabrics, ammonia-mercerized sheetings. scoured, bleached print cloths and scoured, bleached, sodium hydroxide-mercerized print cloths were wash and wear finished by using DMDHEU with the loop transfer applicator

As seen in Tables 1,2 and 3, the DP of the ammonia. merceried and not finished sheeting was suitable, whose value was 2.4. The sodium hydroxide-mercerized fabrics had higher tensile strengths than those of the fabrics not sodium hydroxide-mercerized. The low wet pick-up finished fabrics showed a less reductions in tensile and

Table 1 Finishing of $\mathrm{NH}_{3}$ - Mercerized Cotton Sheeting ${ }^{\mathrm{a}}$

\begin{tabular}{|c|c|c|c|c|c|c|c|c|c|c|c|}
\hline $\begin{array}{l}\text { DMDHEU } \\
\begin{array}{c}(\%) \\
\end{array}\end{array}$ & Cata & & \multicolumn{2}{|l|}{ Softener } & $\begin{array}{c}\text { Wetting } \\
\text { agent } \\
(\%)\end{array}$ & $\begin{array}{l}\text { Pick-up } \\
(\%)\end{array}$ & $\begin{array}{l}\text { Add-on } \\
\text { (\%) }\end{array}$ & $\begin{array}{c}\text { DP } \\
\text { (degree) }\end{array}$ & $\begin{array}{c}\text { WRA } \\
\text { conditioned } \\
(W+F, \text { degree })\end{array}$ & $\begin{array}{c}\text { Tensile } \\
\text { strength } \\
(\mathrm{kgf})\end{array}$ & $\begin{array}{c}\text { Tearing } \\
\text { strength } \\
(\mathrm{gf})\end{array}$ \\
\hline Untrea & ed fabr & & & & & & & 2.4 & 250 & 31.8 & 770 \\
\hline $4.5^{b)}$ & $\mathrm{MgCl}_{2}$ & 1.35 & - & & 0.1 & 71.2 & 0.6 & 3.7 & 282 & 19.0 & 560 \\
\hline 12 & $"$ & 3.6 & - & & - & 30.8 & 1.9 & 3.9 & 294 & 21.1 & 627 \\
\hline 12 & $"$ & 3.6 & - & & 0.2 & 30.6 & 1.4 & 4.4 & 283 & 18.3 & 573 \\
\hline 12 & " & 3.6 & Polyethylene & 0.5 & 0.2 & 30.0 & 1.2 & 4.3 & 290 & 17.7 & 620 \\
\hline 12 & $"$ & 3.6 & Silicone & 0.5 & 0.2 & 30.1 & 1.7 & 4.2 & 289 & 18.9 & 707 \\
\hline $10^{c)}$ & " & 3.0 & Polyethylene & 0.5 & 0.2 & 22.7 & 4.0 & 3.7 & 294 & 20.1 & 613 \\
\hline $20^{d !}$ & " & 6.0 & " & 0.5 & 0.2 & 22.1 & 5.9 & 4.3 & 310 & 18.8 & 587 \\
\hline $10^{e)}$ & $"$ & 3.0 & - & & 0.2 & 31.8 & 4.8 & 4.0 & 295 & 19.6 & 707 \\
\hline 12 Gly & olic acid & 5.0 & Polyethylene & 0.5 & 0.2 & 28.7 & 1.8 & 3.8 & 297 & 19.9 & 820 \\
\hline
\end{tabular}

a) Curing $160^{\circ} \mathrm{C} \times 3 \mathrm{~min}$. b) Finishing with ordinary method (pad.dry cure). c) Hystretch V $29.6 \%$, wetting agent, $0.1 \%: 2$ dips : 2 nips $\left(3.5 \mathrm{~kg} / \mathrm{cm}^{2}\right):$ predry, $60 \mathrm{C} \times 7 \mathrm{~min}:$ add-on, $2.3 \%$. d) Same as above: add on, $1.2 \%$. e) Air fiex TL.41,5\%: silicone, $1 \%:$ wetting agent. $0.1 \%: 2$ dips : 2 nips $\left(3.5 \mathrm{~kg} / \mathrm{cm}^{2}\right)$ : pick.up. $68.1 \%$ : add - on, $2.4 \%$. 
Table 2 Finishing of Scoured and Bleached Cotton Print Cloth ${ }^{a}$

\begin{tabular}{|c|c|c|c|c|c|c|c|c|c|c|c|}
\hline DMDHEU & Catal & & $\begin{array}{l}\text { Softener } \\
(\%)\end{array}$ & & $\begin{array}{l}\text { Wetting } \\
\text { agent } \\
(\%)\end{array}$ & $\begin{array}{l}\text { Pick-up } \\
(\%)\end{array}$ & $\begin{array}{l}\text { Add-on } \\
(\%)\end{array}$ & $\begin{array}{c}\mathrm{DP} \\
\text { (degree) }\end{array}$ & $\begin{array}{c}\text { WRA } \\
\text { conditioned } \\
(W+F, \text { degree })\end{array}$ & $\begin{array}{c}\text { Tensile } \\
\text { strength } \\
\text { (kgf) }\end{array}$ & $\begin{array}{c}\text { Tearing } \\
\text { strength } \\
(\mathrm{gf})\end{array}$ \\
\hline Untrea & ed fabri & & & & & & & 1.5 & 189 & 32.3 & 870 \\
\hline $4.5^{b)}$ & $\mathrm{MgCl}_{2}$ & 1.35 & - & & 0.1 & 85.3 & 1.2 & 4.0 & 252 & 14.9 & 453 \\
\hline 12 & $"$ & 3.6 & - & & - & 32.0 & 1.7 & 4.3 & 267 & 16.1 & 473 \\
\hline 12 & $"$ & 3.6 & - & & 0.2 & 30.2 & 1.2 & 4.6 & 251 & 16.0 & 453 \\
\hline 12 & $"$ & 3.6 & Polyethylene & 0.5 & 0.2 & 29.5 & 1.1 & 4.6 & 263 & 13.7 & 520 \\
\hline 12 & " & 3.6 & Silicone & 0.5 & 0.2 & 30.5 & 1.4 & 4.4 & 264 & 14.5 & 580 \\
\hline Gly & olic acid & 5.0 & Polyethylene & 0.5 & 0.2 & 27.4 & 1.7 & 4.3 & 268 & 17.1 & 627 \\
\hline
\end{tabular}

a) Curing $160^{\circ} \mathrm{C} \times 3 \mathrm{~min}$. b) Finishing with ordinary method (pad-dry.cure).

Table 3 Finishing of Scoured. Bleached and NaOH-Mercerized Cotton Print Cloth ${ }^{\mathrm{a}}$

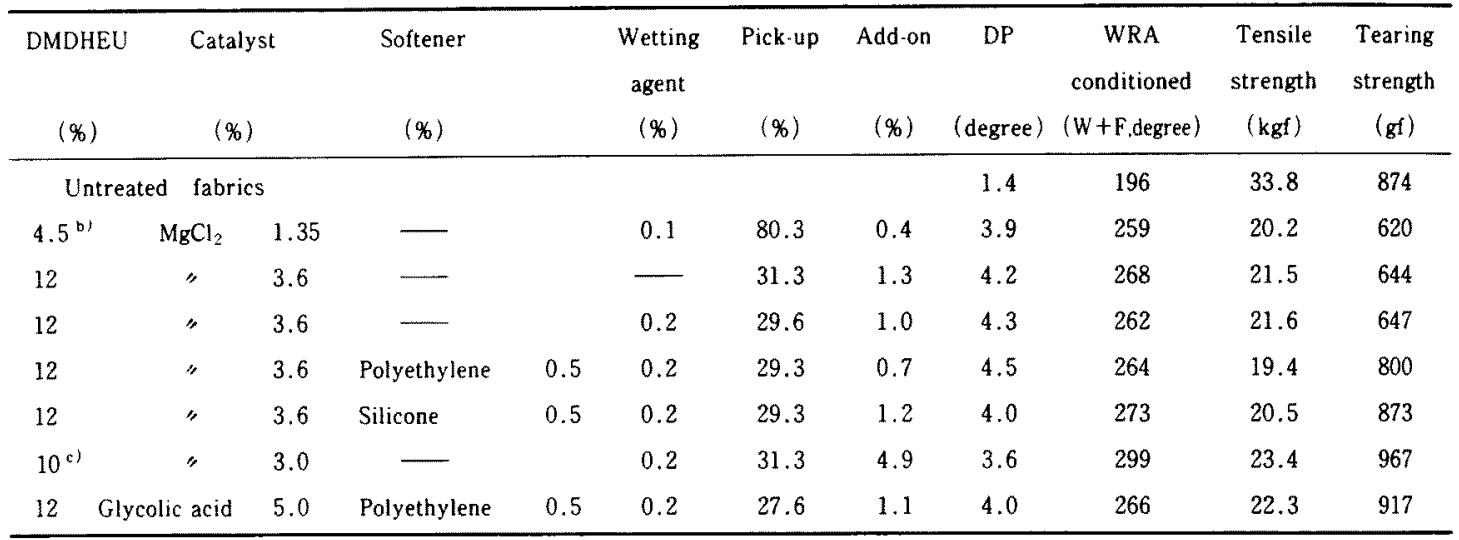

a) Curing $160 \mathrm{C} \times 3 \mathrm{~min}$. b) Finishing with ordinary method (pad-dry-cure). c) Air fiex TL-41,5\%: silicone, $1 \%:$ wetting agent, $0.1 \%$ : 2 dips : 2nips $\left(3.5 \mathrm{~kg} / \mathrm{cm}^{2}\right)$ : pick.up, $78.2 \%$ : add $\cdot 0 \mathrm{n}, 1.4 \%$.

Table 4 Finishing of Thick Cotton Fabrics"

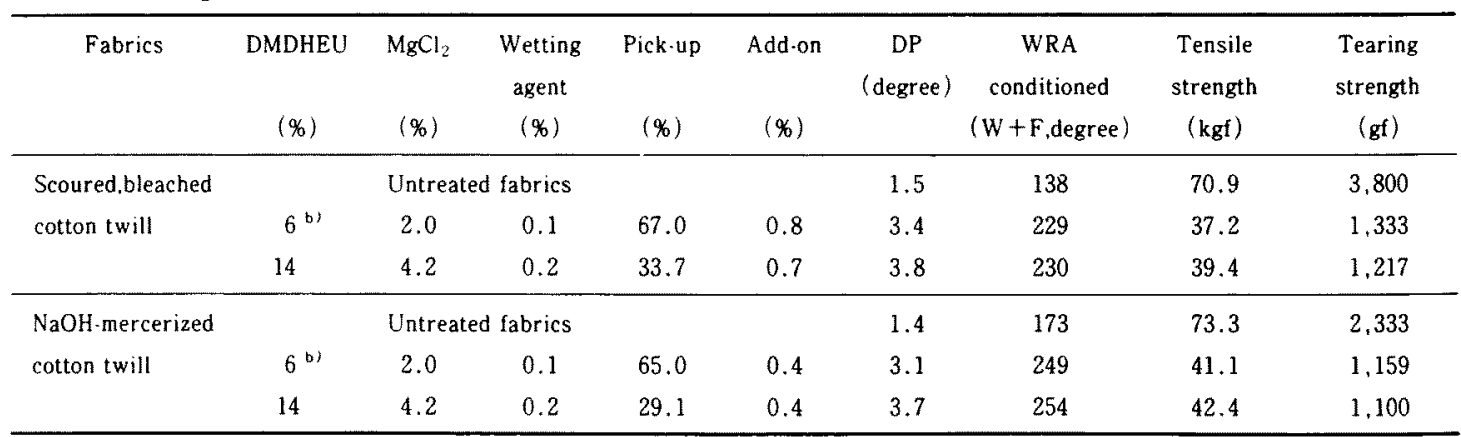

a) Curing $160^{\circ} \mathrm{C} \times 4 \mathrm{~min}$. b) Finishing with ordinary method (pad-dry.cure).

tearing strengths than the ordinarily finished fabrics of the same DP value, for all the kinds of the fabrics. For the low wet pick-up fabrics having a considerably high DP, the tensile strength was significantly lower than that of the ordinarily finished fabrics. However, considering the increase of the DP, the reduction of the tensile strength was relatively small. With the co-use of the softeners, the reduction of the tearing strength was re. markably prevented. For some finished fabrics, the tear. ing strengths were higher than those of the unfinished 
fabrics. The silicone softener was more effective in pre venting the reduction of the tearing strengths than the polyethylene softener. The pretreatment of the fabrics with a thermoplastic resin prevented the reduction of the tensile strengths. In the case of glycolic acid $\left(\mathrm{HOCH}_{2} \mathrm{COOH}\right)$ as catalyst, the reductions in tensile and tearing strengths were low, as compared with the case of magnesium chloride as catalyst. The low wet pick-up finishing rendered higher DP properties and wrinkle recovery and better hand to the fabrics than the ordinary finishing.

The thick cotton fabrics, that is, the scoured, bleached twill and the scoured, bleached, sodium hydroxidemercerized twill were finished next with DMDHEU by means of the loop transfer applicator.

As seen in Table 4 , the tensile strength of the scoured. bleached, sodium hydroxide-mercerized twill was higher than that of the scoured, bleached twill. By the low wet pick-up finishing at a pick-up of ca. $30 \%$, the reduction of the tensile strength was less than that by the ordinary finishing. Considering the high DP, the reduction of the tearing strength was small. The low wet pick-up finishing gave higher DP degree and crease recovery.

As described above, the low wet pick-up finishing was effective in depressing the reductions of the tensile and tearing strengths, giving high DP and wrinkle recovery properties and good hand of the fabrics. This is presumably a result of no migration of the resin during the drying, that is, the absence of the resin at the surface, and the uniformity in the applied resin and the crosslink ing distribution.

It is speculated that, generally, the tearing strength of finished fabrics, which is often an important factor in their practical use, is substantially proportional to the product of the resistance of the spun yarns to impact and the deformation capability of the fabrics for the impact [ 7 ]. Accordingly, the couse of the softeners increases the deformation capability of the fabrics against impact, leading to the less reduction of the tearing strength.

As for the catalysts. glycolic acid was more effective in depressing the reductions of the tensile and tearing strengths than magnesium chioride. For this reason, it is supposed that the cellulose was hydrolyzed to a less degree. The sodium hydroxide-mercerized fabrics exhibited a higher tensile strength due to the less distortion of cot. ton fibers.

It is needless to say that the low wet pick-up finishing contributes to energy-saving. The crosslinking agent is evenly distributed to improve the DP and the wrinkle recovery. Accordingly, the amount of a resin used in the low wet pick-up finishing can be considerably saved as compared with the ordinary finishing, provided that the DP's and the wrinkle recoveries are the same.

\section{References}

1. a) T. Hongu, "New Technology of Textile Finishing" (I. Hashimoto and H. Yokoyama, Eds.). The Textile Machinery Society of Japan, p. 56 (1973) ; b) K. Yamataka. "New Course of Dyeing and Finishing. Finishing ". Vol. 11, No.1 (H. Tonami and H. Sanu ki. Eds.), Kyoritsu Shuppan, p.73 (1972) ; c) T. Masuda and K. Shiozawa, "Technology of Textile Finishing", Chijin Shokan, p.9, p.72 (1976).

2. J. G. Frick, Jr., B. A. K. Andrew, and J. D. Raid, Text Res.J., 29. 314 (1959).

3. R. D. Leah, J. Soc. Dyers Colour, 98, 422 (1982).

4. S. Kubota, Sen'i Kako, 34, $379 ; 438$ (1982).

5. R. J. Harper, Jr., Text. Chem. Color., 11, 125 (1979).

6. 1. b), p. 60 .

7. R. Steele, Am. Dyest. Rep., 46, 329 (1957). 